Check for updates

Cite this: RSC Adv., 2019, 9, 1586

Received 3rd November 2018

Accepted 6th January 2019

DOI: $10.1039 / c 8 r a 09099 h$

rsc.li/rsc-advances

\section{Preparation of triazine containing porous organic polymer for high performance supercapacitor applications $\uparrow$}

\author{
Lirong Xu, (D) *a Ruiying Liu, ${ }^{a}$ Fang Wang, ${ }^{a}$ Shina Yan, ${ }^{a}$ Xinxin Shi ${ }^{a}$ and Jiaqin Yang ${ }^{\star a b}$ \\ By condensing $\mathrm{M}$ and TFP under solvothermal conditions, a new porous organic polymer POP $\mathrm{M}_{\text {-TFP }}$ was \\ obtained. The electrode modified with triazine containing POP $_{M-T F P}$ exhibits well-defined rapid redox \\ processes and showed a high specific capacitance of $130.5 \mathrm{~F} \mathrm{~g}^{-1}$ at $2 \mathrm{~A} \mathrm{~g}^{-1}$, suggesting well \\ electrochemical performance.
}

Due to the overconsumption of oil and coal over the past few decades, it is highly desirable to develop safe sources of energy, as well as the eco-friendly use of conventional energy through energy storage devices. ${ }^{1,2}$ Supercapacitors have attracted much attention because of their high power density, long recycle life and a wide temperature range. ${ }^{3}$ Generally, supercapacitors are classified into two types: electrochemical double layer capacitor and pseudocapacitor. ${ }^{4-6}$ Electrode materials are the key ingredient for this electrochemically occurring process. ${ }^{7}$ The applied voltage depended ion adsorption on the electrode surface depending on the structure of the material used for the electrodes. To obtain a device with good performance, significant study has been paid to the exploration of redox-active materials for supercapacitors. ${ }^{8,9}$ In order to improve the electronic performance of electrode materials, the functionalized porous structure having a high surface area and hierarchical porosity is important. ${ }^{10}$

Nanoporous organic polymers with high nitrogen content have got great interest because of their applications in semiconductors, gas storage, and electrochemical supercapacitors etc. ${ }^{11-13}$ Recently, nitrogen-doped carbon materials exhibit good electrical properties because the pseudocapacitance effect provided by $\mathrm{N}$ atoms..$^{14}$ Nanoporous organic polymers, such as covalent organic frameworks (COFs), covalent triazine-based frameworks (CTFs), porous organic polymers (POPs) which have controllable pore structure and heteroatom doping are promising electrode materials in supercapacitors. ${ }^{15-19}$ Among them, POPs which are built by the polymerization of rigid organic molecules showing good supercapacitor applications

${ }^{a}$ School of Chemistry and Chemical Engineering, Qufu Normal University, Qufu, 273165, Shandong, China. E-mail: xulr2015@qfru.edu.cn; yjq8681@163.com

${ }^{b}$ Key Laboratory of Advanced Energy Materials Chemistry (Ministry of Education), College of Chemistry, Nankai University, Tianjin, 300071, China

$\dagger$ Electronic supplementary information (ESI) available: Experimental details, instrumentation and characterization of $\mathrm{POP}_{\mathrm{M}-\mathrm{TFP}}$, other figures and electrochemical measurements. See DOI: 10.1039/c8ra09099h are TaPa-Py COF, HCPANIs, TpDAB and Aza-CMPs etc. ${ }^{20-23}$ POPs have micropores with high specific surface area and heteroatom doping, which should be quite conductive to the electrochemical performance when applied as electrode materials. Consequently, polytriazines with high surface area stand out due to their high nitrogen content. ${ }^{24}$

Nowadays, nitrogen-enriched polymers attract increasing attention for application in supercapacitors. ${ }^{25}$ It is a challenge to synthesize nitrogen-enriched nanoporous polymers by using cheap reagents. ${ }^{26}$ POPs or COFs are prepared by using different synthetic method such as ultrahigh vacuum surface synthesis, ${ }^{27}$ microwave assisted solvothermal synthesis, ${ }^{28}$ ionthermal synthesis ${ }^{29}$ and vapor-assisted conversion etc. ${ }^{30}$ Solvothermal synthesis often used to produce nanoporous materials through exploring reaction conditions appropriately. ${ }^{31-33}$ CTFs represent a class of functionalized polymers which are obtained by the trimerization of aromatic nitriles under ionthermal conditions in the presence of a catalyst. This method involves harsh experimental conditions such as very high temperature. ${ }^{29}$ Melamine is a trimer of aromatic nitriles, with a 1,3,5-triazine skeleton considered as Lewis base. ${ }^{34}$ The lone pair of electrons in $\mathrm{N}$ plays an important role in electrochemical applications. Introducing triazine skeleton into POP materials by using precursor bearing triazine moieties is a straightforward approach in POP synthesis.

Herein, we choose a trigonal-symmetrical nitrogencontaining melamine (M) as a monomer, which can be used to construct conjugated microporous covalent triazine-based organic polymer through the coupling with triformylphloroglucinol (TFP) monomer under solvothermal conditions without any catalysts. The doping of nitrogen atoms in $\mathrm{POP}_{\mathrm{M}-}$ TFP can affect the electron distribution of the materials and further enhance the wettability and the electro-active surface area of the electrode. Otherwise, the nitrogen atom can also introduce pseudocapacitance to the supercapacitors, which are beneficial for enhancing the supercapacitor performance. 


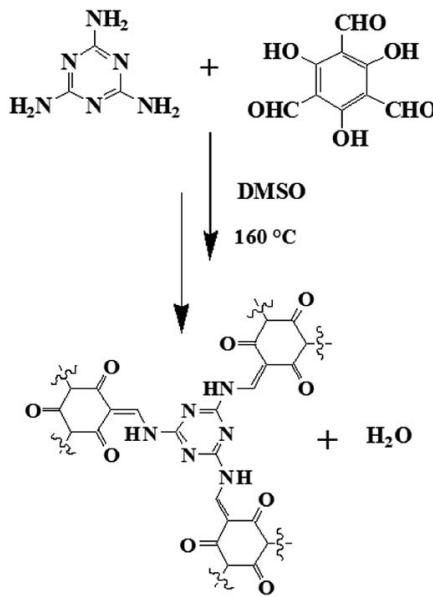

Scheme 1 Schematic representation of the structure of POPM-TFP.

Scheme 1 illustrates the synthesis of $\mathrm{POP}_{\mathrm{M} \text {-TFP }}$ at $160{ }^{\circ} \mathrm{C}$. The synthesized $\mathrm{POP}_{\mathrm{M} \text {-TFP }}$ was employed as an electrode material for supercapacitor application. The electrodes which are modified with POP $_{\mathrm{M} \text {-TFP }}$ exhibit well-defined rapid redox processes and high capacitance.

The crystalline structure of $\mathrm{POP}_{\mathrm{M} \text {-TFP }}$ was first characterized by powder X-ray diffraction (XRD). The XRD pattern of $\mathrm{POP}_{\mathrm{M} \text {-TFP }}$ material has been shown in Fig. 1a which reveals the crystalline nature of the material. As seen from Fig. 1a, the peaks at $5.2^{\circ}$, $9.5^{\circ}$ and $27.6^{\circ}$ are attributed to the corresponding (100), (200) and (201) planes diffractions of $\mathrm{POP}_{\mathrm{M} \text {-TFP }}$ respectively. Successful condensation of $\mathrm{M}$ and TFP under a simple solvothermal conditions without any catalysts yields product, which has been confirmed by ${ }^{13} \mathrm{C}$ CP-MAS NMR and The Fourier transform infrared (FT-IR) spectroscopic investigations. In order to further understand the chemical environment of various types of carbon atoms in $\mathrm{POP}_{\mathrm{M}-\mathrm{TFP}},{ }^{13} \mathrm{C}$ solid state NMR spectroscopy was performed. POP $_{\mathrm{M}-\mathrm{TFP}}$ exhibits a clear signal at
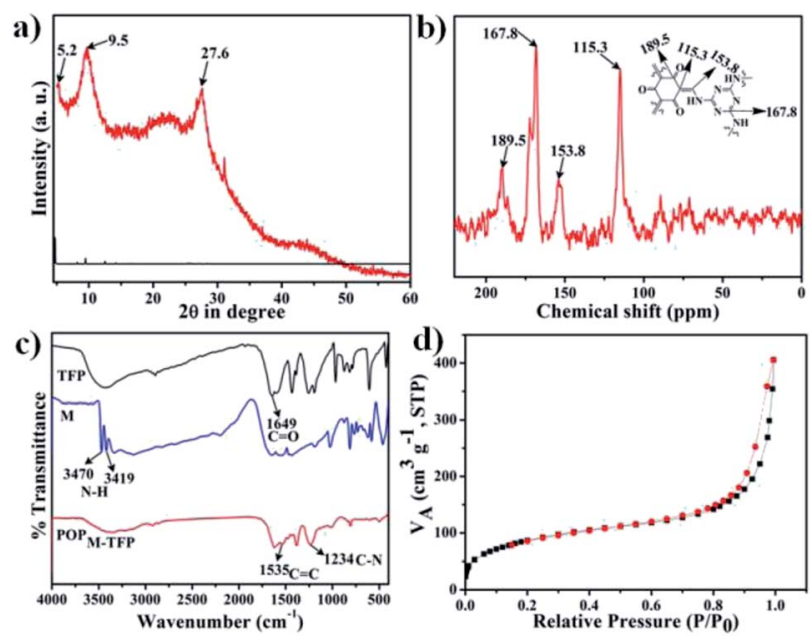

Fig. 1 (a) XRD pattern of POP ${ }_{M-T F P}$ (red) and simulated XRD pattern

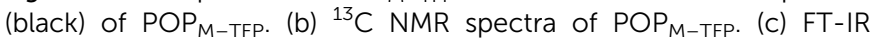
spectrum of $M$, TFP, and POPM-TFP. (d) Nitrogen adsorption/desorption isotherm pattern of $\mathrm{POP}_{M-T F P}$ where black square indicates the adsorption and red circle represents the desorption isotherm.
$167.8 \mathrm{ppm}$ confirms the presence of the triazine skeletons (Fig. 1b). ${ }^{35-37}$ The additional characteristic ${ }^{13} \mathrm{C}$ resonance in the $\mathrm{C}-\mathrm{N}$ was observed to be located at $153.8 \mathrm{ppm}$. The characteristic peak of $\mathrm{C}=\mathrm{O}$ appearing at $189.5 \mathrm{ppm}$. In summary, it can be confirmed that the $\mathrm{M}$ has successfully reacted with TFP to form $\mathrm{POP}_{\mathrm{M}-\mathrm{TFP}}$ material.

The FT-IR spectra of M, TFP and POP $\mathrm{M}_{\mathrm{M} \text {-TFP }}$ between 4000 to $400 \mathrm{~cm}^{-1}$ are shown in Fig. 1c. The two separated peaks at 3470 and $3419 \mathrm{~cm}^{-1}$ originate from stretching vibrations of amine $\left(-\mathrm{NH}_{2}\right)$ groups in $\mathrm{M}$. The peak at $1649 \mathrm{~cm}^{-1}$ belongs to stretching vibrations of $\mathrm{C}=\mathrm{O}$ in TFP. The FT-IR spectra of $\mathrm{POP}_{\mathrm{M} \text {-TFP }}$ shows the disappearance of the $-\mathrm{NH}_{2}$ stretching bands of the $\mathrm{M}$. The appearance of a broad $-\mathrm{NH}$ peak at $3379 \mathrm{~cm}^{-1}$ further indicates the formation of $\mathrm{POP}_{\mathrm{M} \text {-TFP. }}$. Additionally, the emergence of a new band at $1234 \mathrm{~cm}^{-1}$ is characteristic of C-N stretch moieties. The peak at $1535 \mathrm{~cm}^{-1}$ belongs to stretching vibrations of $\mathrm{C}=\mathrm{C}$ in $\mathrm{POP}_{\mathrm{M} \text {-TFP. }}{ }^{16,38}$ Further, the chemical environment of the elements present in the specimen was studied using X-ray photoelectron spectroscopy (XPS). Full scan XPS spectra of $\mathrm{POP}_{\mathrm{M} \text {-TFP }}$ showed in Fig. S1 $\uparrow$ reveals the peaks of $\mathrm{C}, \mathrm{N}$ and $\mathrm{O}$. To analyze the detailed chemical states of $\mathrm{N}$ elements, the high-resolution XPS scan was also recorded (Fig. S2 $\dagger$ ). The $\mathrm{N} 1 \mathrm{~s}$ spectra of $\mathrm{POP}_{\mathrm{M}-\mathrm{TFP}}$ split into two peaks located at $398.8 \mathrm{eV}$ and $399.8 \mathrm{eV}$, respectively. The peak at $398.8 \mathrm{eV}$ can be assigned to triazine $\mathrm{N}$, while the peak at $399.8 \mathrm{eV}$ can be assigned to the $\mathrm{N}$ in the $-\mathrm{C}=\mathrm{C}-\mathrm{NH}-$. These peak positions are in agreement with previous reports. ${ }^{20,35}$ The $\mathrm{N}_{2}$ adsorption/desorption was carried out for $\mathrm{POP}_{\mathrm{M} \text {-TFP }}$ in order to evaluate the permanent porosity. The $\mathrm{N}_{2}$ sorption isotherm measured at $77 \mathrm{~K}$ as showed in Fig. 1d. POP $\mathrm{M}_{\mathrm{TFP}}$ exhibits characteristics of type-I adsorption isotherms with sharp uptake at a low pressure region indicating the microporous nature of this material. The Brunauer-Emmett-Teller (BET) surface area of $\mathrm{POP}_{\mathrm{M} \text {-TFP }}$ was found to be $317 \mathrm{~m}^{2} \mathrm{~g}^{-1}$. The pore size distribution plot has been demonstrated in Fig. S3. $\dagger$ The two sharp peaks at 1.5 and $2.5 \mathrm{~nm}$ are observed from the pore size distribution plot. Micropores of dimension $1.5 \mathrm{~nm}$ could be attributed to the porous network of the $\mathrm{POP}_{\mathrm{M} \text {-TFP }}$, whereas mesopores of $2.5 \mathrm{~nm}$ could be originated due to void spaces associated to the grain boundary.

The morphology of the synthesized POP $_{\mathrm{M} \text {-TFP }}$ can be well investigated by field emission scanning electron microscopy (FE-SEM) and transmission electron microscope (TEM) analysis respectively. FE-SEM images of $\mathrm{POP}_{\mathrm{M} \text {-TFP }}$ at two different magnifications are shown in Fig. 2a and b. SEM images show that $\mathrm{POP}_{\mathrm{M} \text {-TFP }}$ reveals irregular nanowires morphologies. The TEM characterization further confirms the nanowire structures morphology with porous architecture (Fig. $2 \mathrm{c}$ and d.). Fig. $2 \mathrm{~d}$ represents the high-resolution TEM image of $\mathrm{POP}_{\mathrm{M} \text {-TFP }}$ where the micropores of about $1.5 \mathrm{~nm}$ (white spot) are spread throughout the specimen.

Considering the synthesized $\mathrm{POP}_{\mathrm{M} \text {-TFP }}$ with 1,3,5-triazine skeleton distributed in nanopores, this may hold promising applications in electrode materials for supercapacitors. The pore channels and triazine units in $\mathrm{POP}_{\mathrm{M} \text {-TFP }}$ could render this material able to store electric energy. The electrochemical performance of $\mathrm{POP}_{\mathrm{M}-\mathrm{TFP}}$ was investigated by using a typical 


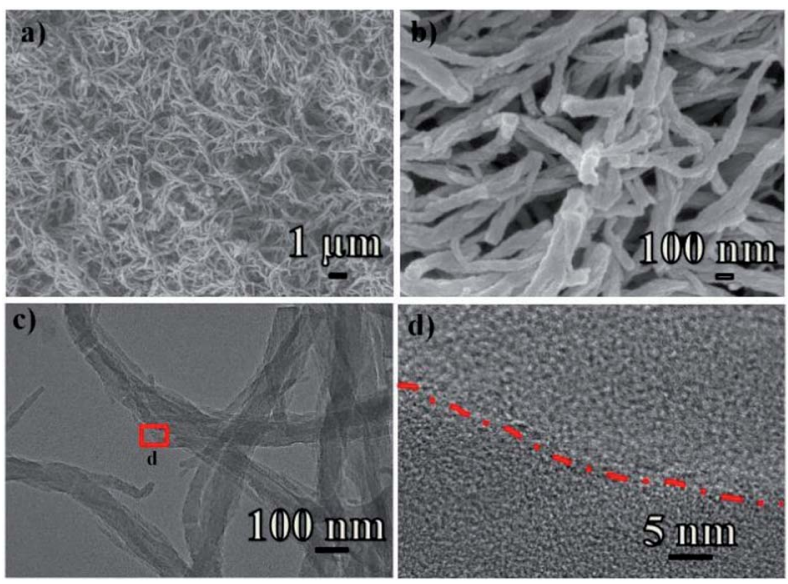

Fig. 2 ( $a$ and b) FE-SEM images of POP ${ }_{M-T F P}$ at two different magnifications. ( $c$ and $d$ ) TEM images of $P_{\text {OP }}$ (TFP at two different magnifications.

three-electrode system in $2 \mathrm{M} \mathrm{KOH}$ aqueous electrolyte. The working electrodes were fabricated by mixing $\mathrm{POP}_{\mathrm{M} \text {-TFP }}$, acetylene black and binder (polyvinylidene fluoride) in a weight ratio of $80: 10: 10$ and loaded to a piece of nickel foam. A Pt plate and $\mathrm{Hg} / \mathrm{HgO}$ electrode were used as the counter electrode and reference electrode, respectively. The electrochemical charge storage activity of the $\mathrm{POP}_{\mathrm{M} \text {-TFP }}$ was analysed by cyclic voltammetry (CV), galvanostatic charge discharge (GCD) and electrochemical impedance spectroscopy (EIS) in $2 \mathrm{M} \mathrm{KOH}$ electrolyte. The $\mathrm{CV}$ curves of $\mathrm{POP}_{\mathrm{M} \text {-TFP }}$ at $5 \mathrm{mV} \mathrm{s}^{-1}, 10 \mathrm{mV} \mathrm{s}^{-1}, 20 \mathrm{mV} \mathrm{s}^{-1}$, $50 \mathrm{mV} \mathrm{s}^{-1}$, and $100 \mathrm{mV} \mathrm{s}^{-1}$ are presented in Fig. 3a. The CV recorded with the as-prepared electrode over different scan rates shows redox peaks at $\sim 0.34-0.45 \mathrm{~V}$ during forward and backward sweeps, suggesting its pseudo capacitive nature. The redox signature is attributed to the oxidation and reduction of the triazine skeleton in the polymer. The small separation between cathodic and anodic peaks indicated that the fast electron transfer kinetics between $\mathrm{POP}_{\mathrm{M} \text {-TFP }}$ and the electrode interface. The current plateau of $\mathrm{CV}$ over the increasing scan
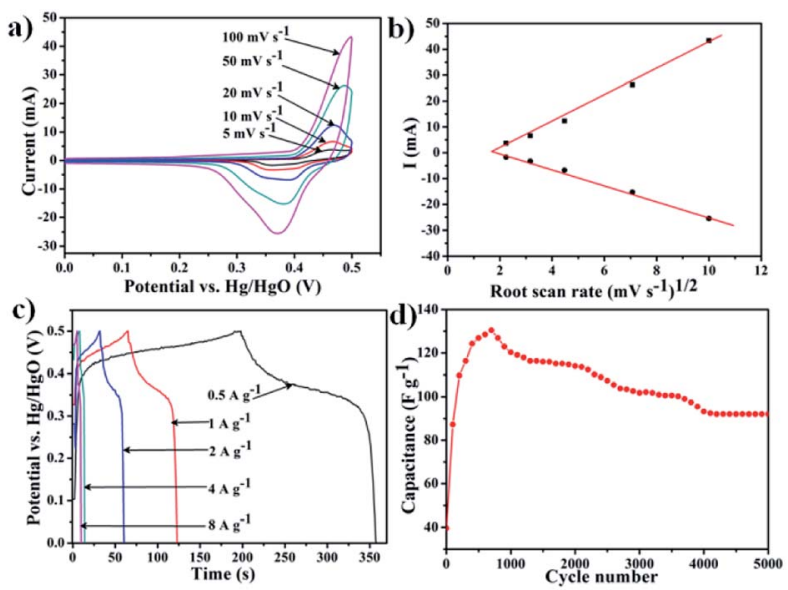

Fig. 3 (a) $C V$ curves of $\mathrm{POP}_{\mathrm{M} \text {-TFP }}$ at different scan rates in $2 \mathrm{M} \mathrm{KOH}$ electrolyte. (b) Peak current vs. $m V^{1 / 2}$ plots of POP $M$-TFP. (c) GCD curves of POP $\mathrm{M}_{\mathrm{M} \text { TFP }}$ at different current densities. (d) Cycling performance of the electrochemical capacitor based on POP $\mathrm{M}_{\text {-TFP }}$ at $2 \mathrm{~A} \mathrm{~g}^{-1}$. rate increased, suggesting fast accessible ions electrolyte through the pore channel of $\mathrm{POP}_{\mathrm{M} \text {-TFP. }}$

The specific capacitance of the electrode materials is estimated from the follow equation, ${ }^{39}$

$$
C_{\mathrm{sp}}=\left(\int I \mathrm{~d} V\right) / v m V
$$

where $I$ represents current, $V$ represents the potential window (V), $v$ indicates scan rate and $m$ stands for the mass of active material in the electrode. The estimated specific capacitance of $\mathrm{POP}_{\mathrm{M}-\mathrm{TFP}}$ material was found to be $105.8 \mathrm{~F} \mathrm{~g}^{-1}$ at $5 \mathrm{mV} \mathrm{s}^{-1}$ scan rate (Fig. S4 $\dagger$ ). With the increase of scan rate the specific capacitance was gradually decreased down. This may be due to the restriction of ion insertion into the pore channels and weak redox kinetics of $\mathrm{POP}_{\mathrm{M} \text {-TFP }}$ at fast scan rates. The appearance of small humps in CV curves around $0.34-0.45 \mathrm{~V}$ can be attributed to the redox reactions of the heteroatom $(\mathrm{N})$ functionalities of the $\mathrm{POP}_{\mathrm{M}-\mathrm{TFP}}$ and nickel foam. Additionally, the $\mathrm{N}$ atoms embedded in POP $_{\mathrm{M} \text {-TFP }}$ are desirable to improve the capacitance by enhancing the electrolyte solution wettability of the electrode materials. ${ }^{40}$ At the slow scan rates, ions have sufficient time to arrive at the surface of $\mathrm{POP}_{\mathrm{M} \text {-TFP }}$, can be able to penetrate through channel of $\mathrm{POP}_{\mathrm{M} \text {-TFP. }}$ Moreover, the peak current is proportional to the root scan rate over the range of 5 to $100 \mathrm{mV} \mathrm{s}^{-1}$, implies that the redox reaction is diffusioncontrolled electron-transfer process presented in Fig. $3 \mathrm{~b} .^{41} \mathrm{~A}$ more detailed investigations on electronic performance for its applicability as a supercapacitor electrode material is analyzed by GCD. The GCD curves of $\mathrm{POP}_{\mathrm{M} \text {-TFP }}$ at various current densities ( 0.5 to $8 \mathrm{~A} \mathrm{~g}^{-1}$, Fig. 3c) corroborate with the above $\mathrm{CV}$ results and display clear voltage plateaus at the same voltage position. The nonlinearity of the charge-discharge curve verifies the pseudo capacitance behavior of $\mathrm{POP}_{\mathrm{M}-\mathrm{TFP}}$ due to faradic reaction occurs at the electrode surface. Their symmetric shapes reveal the fast reaction kinetics and high electrochemical reversibility. ${ }^{42}$ An almost negligible IR drop was observed in the GCD curve indicating a minute ohmic resistance and good capacitive performance. The specific capacitance of $\mathrm{POP}_{\mathrm{M}-\mathrm{TFP}}$ over different current densities is estimated from eqn (2),

$$
C_{\mathrm{sp}}=\frac{(I \times \Delta t)}{\Delta V \times m}
$$

where $I$ is current, $\Delta V$ represents potential window (V), $\Delta t$ signifies discharge time (s) and $m$ represents the mass of active material. The highest specific capacitance of $\mathrm{POP}_{\mathrm{M} \text {-TFP }}$ is calculated to be $130.5 \mathrm{~F} \mathrm{~g}^{-1}$ at $2 \mathrm{~A} \mathrm{~g}^{-1}$. The cycle performance of POP $_{\mathrm{M} \text {-TFP }}$ was evaluated by GCD test at $2 \mathrm{~A} \mathrm{~g}^{-1}$ as showed in Fig. 4d. The highest specific capacitance $130.5 \mathrm{~F} \mathrm{~g}^{-1}$ achieved after 130 cycling. The high specific capacitance of $\mathrm{POP}_{\mathrm{M}-\mathrm{TFP}}$ is attributed to better utilization of the porous structure, presence of triazine units, which could provide numerous active sites for ion transfer. It shows a slow loss of the specific capacitance, which reaches $120.2 \mathrm{~F} \mathrm{~g}^{-1}$ after 1000 cycles. Long-term GCD cycling revealed a decrease of specific capacitance could be ascribed to the collapse of the electrode structures. The specific capacitances of $\mathrm{POP}_{\mathrm{M}-\mathrm{TFP}}$ were also calculated from GCDs and 

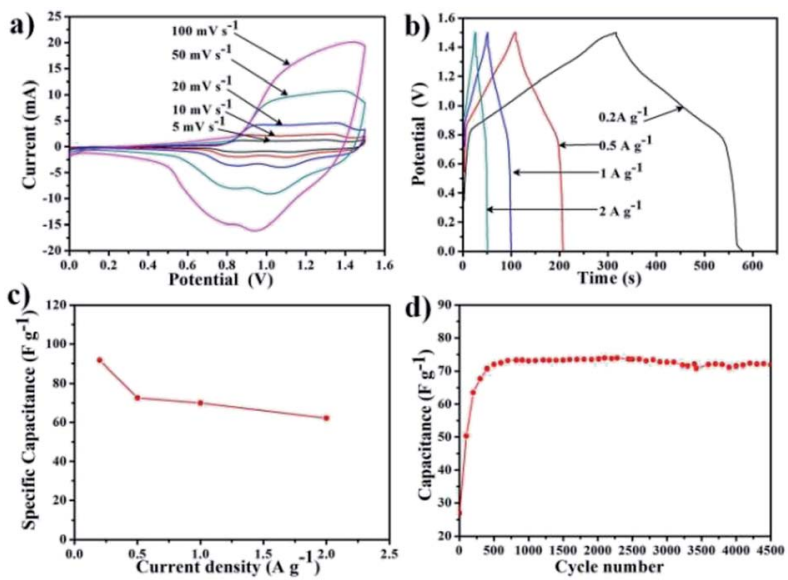

Fig. 4 Electrochemical performance of $\mathrm{POP}_{\mathrm{M}-\mathrm{TFP}}$ in an asymmetry supercapacitor cell in $2 \mathrm{M} \mathrm{KOH}$. (a) $\mathrm{CV}$ curves of $\mathrm{POP}_{\mathrm{M} \text {-TFP }}$ at different scan rates in the potential window of 0-1.5 V. (b) GCD profiles at various current densities. (c) Corresponding specific capacitances of the asymmetric cell. (d) Cycling performance test of POPM-TFP at $0.5 \mathrm{~A} \mathrm{~g}^{-1}$.

compared as showed in Fig. S5. $\dagger$ The highest specific capacitance of POP ${ }_{\mathrm{M} \text {-TFP }}$ is calculated to be $178.0 \mathrm{~F} \mathrm{~g}^{-1}$ at $0.5 \mathrm{~A} \mathrm{~g}^{-1}$, 137.4 $\mathrm{F} \mathrm{g}^{-1}$ at $1 \mathrm{~A} \mathrm{~g}^{-1}, 130.5 \mathrm{~F} \mathrm{~g}^{-1}$ at $2 \mathrm{Ag}^{-1}, 86.4 \mathrm{~F} \mathrm{~g}^{-1}$ at $4 \mathrm{Ag}^{-1}$ and $76.9 \mathrm{~F} \mathrm{~g}^{-1}$ at $8 \mathrm{~A} \mathrm{~g}^{-1}$ respectively. With increasing the current density, the specific capacitance of $\mathrm{POP}_{\mathrm{M}-\mathrm{TFP}}$ tends to decrease. A slight decrease in the specific capacitance values with the increased current density is believed to be due to the hierarchical pore structure, which facilitates the smooth transfer of ions at higher current densities. Additionally, most of the active sites triazine moieties on the electrode surface are accessible to electrolyte. This material has the advantage as electrode material because of inherent stacking behavior between two adjacent layers, which can provide a nanoscale channel to the stacking direction. Owing to the presence of stacking phenomena, the presence of triazine moieties in the POP $_{\mathrm{M} \text {-TFP }}$ can expedite the ion transfer through porous channels. Extended $\pi$-conjugation and ion conduction inside the pores throughout $\mathrm{POP}_{\mathrm{M}-\mathrm{TFP}}$, the redox processes arising from triazine units could be responsible for this high supercapacitor performance.

Furthermore, the interfacial charge transfer activity and electrocapacitive characteristics of POP $_{\mathrm{M}-\mathrm{TFP}}$ are studied by EIS analysis. The impedance characteristic of the electrode is represented by a Nyquist plot (Fig. S6 $\dagger$ ). From the analysis of the Nyquist plots, $\mathrm{POP}_{\mathrm{M} \text {-TFP }}$ displays a near vertical line within the low-frequency region, indicative of a well capacitive behavior. The slope of the line at low frequency region is related to the diffusive resistivity of the electrolyte ions within the nanopores. The small semicircular shapes in the EIS plots in the high frequency could be neglected indicates a low charge transfer resistance at the electrode/electrolyte interface (inset in Fig. S3 $\dagger) .{ }^{43}$ We also estimated the accessible electro-active sites of $\mathrm{POP}_{\mathrm{M} \text {-TFP }}$ system by the method already discussed in the previous literature. ${ }^{16,20}$ These calculations suggest the about $1.99 \%$ of the triazine moieties are accessible.
To evaluate the energy and power density, the supercapacitor performance of $\mathrm{POP}_{\mathrm{M} \text {-TFP }}$ was tested in two electrode system using $2 \mathrm{M} \mathrm{KOH}$ as electrolyte. Activated carbon and as-prepared POP $_{M-T F P}$ were used as negative and positive electrodes in the asymmetric supercapacitor fabrication, respectively. The asymmetric supercapacitor was investigated in the potential window of 0 to $1.5 \mathrm{~V}$ at different scan rates (Fig. 4a). The current increases with increasing scan rate suggesting a good rate capability for energy storage. The CV curves and GCD curves (Fig. 4b) indicated their typical pseudo capacitive behaviour. The calculated specific capacitances of the supercapacitor at different current densities are summarized in Fig. 4c. The specific capacitance at current density of $0.2 \mathrm{~A} \mathrm{~g}^{-1}$ was $91.7 \mathrm{~F}$ $\mathrm{g}^{-1}$. The highest energy density and power density were calculated to be $25.8 \mathrm{~W} \mathrm{~h} \mathrm{~kg}^{-1}$ and $727 \mathrm{~W} \mathrm{~kg}^{-1}$, respectively (Fig. S7†). The cycle life of the asymmetric supercapacitor was further investigated at $0.5 \mathrm{~A} \mathrm{~g}^{-1}$ (Fig. 4d). The specific capacitance retained 72.5 after 4500 GCD cycles at current density of $0.5 \mathrm{~A} \mathrm{~g}^{-1}$, demonstrating the outstanding stability of the device.

In summary, by a simple solvothermal synthesis method, we have successfully synthesized a crystalline triazine containing porous organic polymer POP $_{M-T F P}$ through simple condensation reaction between $\mathrm{M}$ and TFP using dimethyl sulfoxide solvent without any catalysts. Further, we have used POP $_{M-T F P}$ as an electrode material for supercapacitor application. The electrochemical measurement of POP $_{\mathbf{M}-\mathrm{TFP}}$ material showed well electro-chemical performance in supercapacitors. The wonderful electrochemical properties of the POP $_{\mathbf{M - T F P}}$ can be ascribed to the synergistic effect of the $\pi$-conjugated triazine contained POP $_{\mathbf{M - T F P}}$ and nanopores structure. Active sites triazine moieties which put up redox behavior distributed in the pore channels. These findings will meet the requirements like energy storage ability and help more energy efficient electrode materials in the near future.

\section{Conflicts of interest}

There are no conflicts to declare.

\section{Acknowledgements}

This work was supported by the National Natural Science Foundation of China (21505085).

\section{Notes and references}

1 B. Dunn, H. Kamath and J.-M. Tarascon, Science, 2011, 334, 928.

2 X. Liu, N. Wen, X. Wang and Y. Zheng, ACS Sustainable Chem. Eng., 2015, 3, 475.

3 M. Beidaghi and Y. Gogotsi, Energy Environ. Sci., 2014, 7, 867. 4 A. M. Khattak, H. Yin, Z. A. Ghazi, B. Liang, A. Iqbal, N. A. Khan, Y. Gao, L. Li and Z. Tang, RSC Adv., 2016, 6, 58994.

5 J. P. Paraknowitsch and A. Thomas, Energy Environ. Sci., 2013, 6, 2839. 
6 C. Merlet, B. Rotenberg, P. A. Madden, P.-L. Taberna, P. Simon, Y. Gogotsi and M. Salanne, Nat. Mater., 2012, 11, 306.

7 Y. Kou, Y. Xu, Z. Guo and D. Jiang, Angew. Chem., Int. Ed., 2011, 50, 8753.

8 C. Wang, Y. Xi, M. Wang, C. Zhang, X. Wang, Q. Yang, W. Li, C. Hu and D. Zhang, Nano Energy, 2016, 28, 115.

9 C. R. Mulzer, L. Shen, R. P. Bisbey, J. R. McKone, N. Zhang, H. D. Abruna and W. R. Dichtel, ACS Cent. Sci., 2016, 2, 667.

10 S.-Y. Ding and W. Wang, Chem. Soc. Rev., 2013, 42, 548.

11 K. Sakaushi, G. Nickerl, H. C. Kandpal, L. Cano-Cortes, T. Gemming, J. Eckert, S. Kaskel and J. van den Brink, J. Phys. Chem. Lett., 2013, 4, 2977.

12 S. Hug, L. Stegbauer, H. Oh, M. Hirscher and B. V. Lotsch, Chem. Mater., 2015, 27, 8001.

13 L. Hao, B. Luo, X. Li, M. Jin, Y. Fang, Z. Tang, Y. Jia, M. Liang, A. Thomas, J. Yang and L. Zhi, Energy Environ. Sci., 2012, 5, 9747.

14 T. Lin, I. W. Chen, F. Liu, C. Yang, H. Bi, F. Xu and F. Huang, Science, 2015, 350, 1508.

15 L. Xu, Y. Yu, J. Lin, X. Zhou, W. Q. Tian, D. Nieckarz, P. Szabelski and S. Lei, Nanoscale, 2016, 8, 8568.

16 C. R. DeBlase, K. E. Silberstein, T. Thanh-Tam, H. D. Abruna and W. R. Dichtel, J. Am. Chem. Soc., 2013, 135, 16821.

17 C. R. DeBlase, K. Hernandez-Burgos, K. E. Silberstein, G. G. Rodriguez-Calero, R. P. Bisbey, H. D. Abruna and W. R. Dichtel, ACS Nano, 2015, 9, 3178.

18 L. Hao, J. Ning, B. Luo, B. Wang, Y. Zhang, Z. Tang, J. Yang, A. Thomas and L. Zhi, J. Am. Chem. Soc., 2015, 137, 219.

19 Y. Su, Y. Liu, P. Liu, D. Wu, X. Zhuang, F. Zhang and X. Feng, Angew. Chem., Int. Ed., 2015, 54, 1812.

20 A. M. Khattak, Z. A. Ghazi, B. Liang, N. A. Khan, A. Iqbal, L. Li and Z. Tang, J. Mater. Chem. A, 2016, 4, 16312.

21 V. Sharma, S. Khilari, D. Pradhan and P. Mohanty, RSC Adv., 2016, 6, 56421.

22 B. C. Patra, S. Khilari, L. Satyanarayana, D. Pradhan and A. Bhaumik, Chem. Commun., 2016, 52, 7592.

23 X. Zhan, Z. Chen and Q. Zhang, J. Mater. Chem. A, 2017, 5, 14463.

24 J. Zhang, Z. Wang, L. Li, J. Zhao, J. Zheng, H. Cui and Z. Zhu, J. Mater. Chem. A, 2014, 2, 8179.
25 Y. Li, S. Zheng, X. Liu, P. Li, L. Sun, R. Yang, S. Wang, Z.-S. Wu, X. Bao and W.-Q. Deng, Angew. Chem., Int. Ed., 2018, 57, 7992.

26 W. Wang, Y. Yuan, F.-X. Sun and G.-S. Zhu, Chin. Chem. Lett., 2014, 25, 1407.

27 B. Yang, J. Bjork, H. Lin, X. Zhang, H. Zhang, Y. Li, J. Fan, Q. Li and L. Chi, J. Am. Chem. Soc., 2015, 137, 4904.

28 H. Wei, S. Chai, N. Hu, Z. Yang, L. Wei and L. Wang, Chem. Commun., 2015, 51, 12178.

29 P. Kuhn, M. Antonietti and A. Thomas, Angew. Chem., Int. Ed., 2008, 47, 3450.

30 D. D. Medina, J. M. Rotter, Y. Hu, M. Dogru, V. Werner, F. Auras, J. T. Markiewicz, P. Knochel and T. Bein, J. Am. Chem. Soc., 2015, 137, 1016.

31 C. S. Diercks and O. M. Yaghi, Science, 2017, 355, 923.

32 F. J. Uribe-Romo, J. R. Hunt, H. Furukawa, C. Klock, M. O'Keeffe and O. M. Yaghi, J. Am. Chem. Soc., 2009, 131, 4570.

33 M. G. Schwab, B. Fassbender, H. W. Spiess, A. Thomas, X. Feng and K. Muellen, J. Am. Chem. Soc., 2009, 131, 7216.

34 N. Sahiner, S. Demirci and K. Sel, J. Porous Mater., 2016, 23, 1025.

35 X. Huang, Z. Wu, H. Zheng, W. Dong and G. Wang, Green Chem., 2018, 20, 664.

36 Y. Cui, Z. Ding, X. Fu and X. Wang, Angew. Chem., Int. Ed., 2012, 51, 11814.

37 B. Jurgens, E. Irran, J. Senker, P. Kroll, H. Muller and W. Schnick, J. Am. Chem. Soc., 2003, 125, 10288.

38 S. Chandra, T. Kundu, K. Dey, M. Addicoat, T. Heine and R. Banerjee, Chem. Mater., 2016, 28, 1489.

39 Y. Ma, W. Chen, P. Zhang, F. Teng, J. Zhou, X. Pan and E. Xie, RSC Adv., 2014, 4, 47609.

40 J.-W. Jeon, R. Sharma, P. Meduri, B. W. Arey, H. T. Schaef, J. L. Lutkenhaus, J. P. Lemmon, P. K. Thallapally, M. I. Nandasiri, B. P. McGrail and S. K. Nune, ACS Appl. Mater. Interfaces, 2014, 6, 7214.

41 W. Lv, M. Guo, M.-H. Liang, F.-M. Jin, L. Cui, L. Zhi and Q.-H. Yang, J. Mater. Chem., 2010, 20, 6668.

42 F. Zhao, Y. Wang, X. Xu, Y. Liu, R. Song, G. Lu and Y. Li, ACS Appl. Mater. Interfaces, 2014, 6, 11007.

43 J. Romero, D. Rodriguez-San-Miguel, A. Ribera, R. MasBalleste, T. F. Otero, I. Manet, F. Liscio, G. Abellan, F. Zamora and E. Coronado, J. Mater. Chem. A, 2017, 5, 4343. 